\title{
COVID-19 - nurses and midwives impact on global security
}

In the year of the nurse and midwife, a global pandemic is not what we signed up for. Nor were we to predict how the world would be turned upside down with grief and devastation across the globe coupled with lethal economic impact. At the commencement of 2020 the World Health Organization (WHO) designated this year as the Year of the Nurse and Midwife in recognition of the contribution nurses and midwives make to peoples lives everyday. Nurses and midwives are the very fabric of healthcare and now we have learnt in real-time that health is an essential component to global security and economic stability. The value that nurses and midwives bring is health security; without them we would see fragile systems dangerously vulnerable to collapse, in the shadow of this global crisis. Now there is extraordinary recognition, but in ways we would have never predicted.

The widespread havoc, catastrophe, and insecurity has left the world scrambling for essential supplies, workforce, equipment, health resources, medical breakthroughs, and economic solutions. Whilst the pandemic is set to near wipe out the world's economy, many low-resourced countries are still fighting major outbreaks of other infectious diseases such as Ebola, and controllable infectious diseases like measles are making a vicious return. Cholera, a disease of the Middle Ages, continues to strike and bring devastation to millions across low resourced countries. What have we learnt? It is distressing to know that these diseases exist when we know how to prevent them and the importance of public health systems in maintaining our global health security. Whilst Australia is in the grip of the SARS-CoV-2 (COVID-19) crisis, there is no doubt it should be taken seriously, our best defense at present is strong public health messaging regarding behaviour change, coupled with a resilient and well-resourced health workforce. Across every facet of the health crisis are committed nurses and midwives who are mission critical to communities' health outcomes.

What's past is prologue; it's fair to say that the impact of COVID-19 was not something the health system had prepared for. The impact the pandemic has had and will continue to have on our health system and every day lives will change the future and our way of living for years to come. While the world battles the pandemic on all fronts, mental health is currently the great sleeper issue. The blast zone of this pandemic will be its psychosocial impact. When we do emerge from isolation, businesses start again and life begins to resemble something like normal - whenever that may be - other areas may take much longer. The warning that more people will suffer from anxiety, fear, and post-traumatic stress will take a significant toll on the community for years to come. Preparedness is focused on the here and now, and perhaps even the next six months, but we must also be planning now for two, five and ten years time as the impact will be wide ranging and hidden if we do not seek it out. One in five Australians already battle a mental illness and there is no doubt this number will increase. Connectedness and support is a critical consideration for the future. Preparing the health workforce to support the community and for the community to support the health workforce as the days ahead will be long and hard is the challenge we now need to equip ourselves for, and translate innovative opportunities for long-lasting benefit.

However, I would argue there are some positives emerging. The relentless impact of COVID-19 has resulted in the speed we have witnessed change, for example the evolution of the adoption of technology, government policy, and legislation, which in the past may linger for months or years. It has been refreshing to not be bombarded by media-fueled populist politics and stalemates in policy decision-making driven by bureaucracy. The bickering over the cost of public healthcare and job losses. The vacuum created by our relatively safe and prosperous world has disappeared. The opportunity to enact creative thinking by necessity has resulted in a new way of working, rapid access to health equipment, increased production to meet demand in certain areas and in amongst all of this has been a spotlight on the incredible work nurses and midwives do every day. On the front line there is no doubt that nurses, midwives, medical, allied health and other hospital staff have a massive challenge ahead of them and it is an investment we all need to support.

It has been said we face an enemy without a flag or a face. In response, public trust and societal stability has been tested. This was demonstrated by panic buying, disappearance of medical supplies, and for many a feeling and sense of deep loss, sadness, loneliness, isolation fatigue, fear, and the unknown. We know the pandemic will resolve, but it is the ability to cope, in the here and now and the wake of destruction that is unknown. It is happening and we need to work out how to proceed. Deep in this uncertainty are nurses and midwives working to ensure care is delivered to those who need it every day, now deployed to COVID-19 clinics and managing infectious clinics, tending to those diagnosed with COVID-19. Challenged by having to wear protective clothing all shift and then to walk out from the shift, returning to their family, knowing they must go back tomorrow, all the while wondering if (or when) they will contract the illness. Some 
have now chosen to distance themselves from their family, and their friends are, understandably, not taking the risk to see them. Such behaviours are indicative of a challenge bigger than any of us as individuals, so as a society we must respond.

So how do we weather the storm and where do we find the silver lining, together, in this twin crisis? A global health pandemic, and an economic crisis the likes the world has not seen since the Great Depression. These uncertain times provide opportunities to re-evaluate operations and lower former obstacles such as utilisation of innovative technology resulting in the optimisation of telehealth and mobile technology, expedite access to data, utilisation of registries, cloud-based platforms, the value of clinical research networks, artificial intelligence for health initiatives, health algorithms changing how we work and where we work enabling reach to where it is needed. The awareness and crucial role nurses and midwives are having on our health system is paramount. The results behavioural change at a population level can achieve to 'flatten the curve' when we stand together is immense. Noting that distancing is having one of the greatest impacts, rapid change sees growth and opportunity such as the importance to pull together as a nation.

April 7, 2020 was World Health Day and deliberately coincided with the release of the first publication of the WHO The State of the World's Nursing Report to mark The Year of the Nurse and Midwife. This report provides us with a detailed snapshot of the nursing workforce globally. The focus is to build our future workforce, continue to foster leadership, quality care and drive policy. Leadership that is greater than a role and title but is responsive, engaged, drives innovation, and has the will to act.

It is not by coincidence the WHO theme for 2020, Nurses: A Voice to Lead - Nursing the World to Health was decided, with many stories of true altruism, heroic leadership, delivering quality care to those at greatest need across the world, in a world where there is fear and uncertainty, Nurses and midwives continue to provide hope and quality care. Whilst there has not been the fanfare and celebrations that nurses and midwives may have hoped for in the Year of the Nurse and Midwife, what has emerged in the wake of this COVID-19 crisis is the worldwide awareness of the critical role nurses and midwives play to global security - a message that no coordinated media campaign could have achieved.

\section{Professor Marion Eckert}

Director, Rosemary Bryant AO Research Centre

Professor of Cancer Nursing

UniSA, Clinical and Health Sciences

University of South Australia

Adelaide, South Australia

Australia 